\title{
Situated learning in the mobile age: mobile devices on a field trip to the sea
}

\author{
Vanessa D.I. Pfeiffer $^{\mathrm{a} *}$, Sven Gemballa ${ }^{\mathrm{a}}$, Halszka Jarodzka ${ }^{\mathrm{b}}$, Katharina Scheiter ${ }^{\mathrm{a}}$ and \\ Peter Gerjets ${ }^{\mathrm{b}}$
}

${ }^{a}$ Department of Zoology, University of Tuebingen, Tuebingen, Germany; ${ }^{b}$ Knowledge Media Research Center, Tuebingen, Germany

(Received 15 January 2009; final version received 23 July 2009)

\begin{abstract}
This study focuses on learning about fish biodiversity via mobile devices in a situated learning scenario. Mobile devices do not only facilitate relating the presented information to the real world in a direct way; they also allow the provision of dynamic representations on demand. This study asks whether mobile devices are suited to support knowledge acquisition in a situated learning scenario and whether providing dynamic content is an additional benefit of mobile devices in combination with a real-world experience. The study was conducted during a regular university course at the Mediterranean Sea. Students had to acquire knowledge on 18 Mediterranean fish species by using either static $(n=16)$ or dynamic learning materials $(n=17)$. An initial classroom activity was followed by a real-world experience with mobile devices (snorkelling activity). Learning outcomes were measured before and after snorkelling. A $2 \times 2$ mixed ANOVA revealed that students performed better after than before the mobile learning experience, whereas no main effect for learning material could be found. However, an interaction between both factors indicated that the knowledge gain in the dynamic group exceeded the knowledge gain in the static group. These results indicate that mobile devices are helpful to unfold the potential of dynamic visualisations for learning biodiversity in a situated learning scenario.
\end{abstract}

Keywords: dynamic visualisations; mobile learning; situated learning; biodiversity

\section{Introduction}

Mobile learning (m-learning) has been shown to improve learning and motivation of students compared to more traditional learning methods (Chen et al. 2004; Liu et al. 2007) and to be suited to putting situated learning into practice (Naismith et al. 2006). Still, it has to be investigated in which educational situations mobile devices play a unique role and how learning activities accomplished with these devices should be designed (Milrad 2007). One requirement that mobile devices can conform to is the fact that animations, videos and any sort of dynamic video material can be provided in any situated learning context, which would not be possible when being confined to print media. For instance, learning about biodiversity traditionally takes place outside the classroom, where static visualisations of different species can be looked up in comprehensive field guidebooks that are intended to help students to classify an

*Corresponding author. Email: vanessa.pfeiffer@uni-tuebingen.de 
observed species (for the domain addressed here see e.g. Bergbauer and Humberg 1999; Louisy 2002). While the information contained in static pictures may be sufficient for experts, who already have available comprehensive knowledge on a species movement, behaviour and habitat, novices may require a richer presentation to compare their field observations to. For novices, videos presented on mobile devices might act as a substitute for an expert's former learning experiences.

To test this assumption, the current study was conducted during a regular university field course for biology students. It was investigated whether the unique possibility of mobile devices, namely, offering dynamic learning material, would enhance learning in a situated scenario, where learners were required to identify fish species while snorkelling. Moreover, it addressed the practicalities of using mobile devices in this type of context.

\section{Theoretical and empirical background}

M-learning has been already successfully implemented in order to support biology education (Chen et al. 2004; Rogers et al. 2004; Mitchell and Race 2005). In these studies, different kinds of technology were implemented in various scenarios, which illustrate the broad range covered by the term m-learning. In the current study we address the role of m-learning for teaching students to identify living species, a crucial ability of biologists, whereby m-learning is referred to as mobility in terms of technology as well as in terms of the learner her/himself, who learns across different contexts (cf. O’Malley et al. 2003). In the following, we consider three issues of m-learning (cf. Milrad 2007; Sharples 2007): (1) the use of mobile technology as a link between informal learning and formal education; (2) the evaluation of an m-learning scenario, and (3) the design of learning activities in m-learning. We augment the last aspect for the learning content itself, as contents may differ in how they can be linked to real-world experience.

\section{Situated learning with mobile devices as a bridge between formal school settings and outdoor scenarios}

A gap has often been observed between formal school settings and real-life problem solving (Resnick 1987). In school, individual and subject-bounded activities dominate, whereas in real life collaboration and interaction with real environments are needed to solve a problem. Moreover, tasks in school are often decontextualised and have to be solved without any tools based on abstract reasoning, whereas real-life problems are usually embedded in a context and tools are available to solve them. Accordingly, it has often been argued that knowledge acquired in formal settings remains inert and cannot be transferred to real-world problems (Bransford, Sherwood, and Sturdevant 1987). Thus, a learning scenario that connects formal school and outof-school settings might facilitate knowledge transfer and its application in different contexts.

Real world experiences are considered to be highly efficient for understanding (Falk and Dierking 2000), and mobile devices might serve as mediating tools that enrich the real-world experience by transporting information used in the classroom to the real world to support the learning process itself (Winters 2007). Mobile devices support this process, since they enable learner-centred, collaborative, situated, contextual, ambient, and anytime-anywhere learning. Moreover, since they are portable, 
ubiquitous, and their information is durable, they overcome the gap between the classroom and the real-life situations envisioned (Naismith et al. 2006). In sum, they might reduce the discrepancy between informal learning and traditional classroom education (Sharples 2007).

However, using mobile technologies in the field may also raise problems. In particular, learners have to change their focus of attention from the real-world situation to a specific device and vice versa (Beale 2007). For this reason, Göth, Frohberg, and Schwabe (2006) outline requirements for operating mobile devices, upon which we designed our study. First, mobile devices should only be used discontinuously in specific situations. In the current study learners could use the mobile devices only on the beach, but not in the water. Both locations were linked to different activities (i.e. observing fish species in the water and determining them on the beach), thereby enabling the required focus switches. The mobile devices were in the foreground focus on the beach, while they were in the background in the water. Second, Göth and colleagues (2006) recommend that mobile devices should not have too many functions, so as to avoid overwhelming learners' attentional resources. Hence, we chose a low-tech device, namely a portable DVD player as hardware without any communication options. In choosing this kind of mobile device, we are aware of omitting some issues of m-learning that are possible with high tech devices; however, constraining interactivity to very few options allowed more precise conclusions to be made concerning the question of what makes m-learning effective. Third, the information access was confined to contents required in the given scenario and hence adapted to it (cf. Ting 2005). This was done by presenting only fish species on the multimedia DVD that could actually be observed in shallow water $(2-5 \mathrm{~m})$ in the area where the study was conducted.

Hence, following recent m-learning theoretical frameworks great care was taken to design the way the technology was integrated into the learning scenario (cf. Sharples 2005). For instance, Taylor et al. (2006) address the dialectic approach of mobile learning based on the activity theory of Engeström (1987). This theoretical perspective focuses on how technology and learning interact with each other (Sharples, Taylor, and Vavoula 2005). The learning scenario of the current study comprises a mobile learner, who is supported by a trained teacher during a field trip with a focus on learning outside the classroom. This out-of-classroom scenario of a snorkelling field trip discloses a new learning space: the sea. Thus, our scenario enables the main aspects of m-learning according to theoretical frameworks, like learner control (e.g. Kolb 1984), conversation with teachers and other students (Pask 1976), contextualisation of the knowledge (Sharples 2005), and constructing knowledge by solving problems and relating new experiences to existing knowledge (Brown and Campione 1996). Moreover, the scenario guaranteed a high ecological validity for the evaluation of mobile learning as will be discussed in the next section.

\section{Evaluating the effectiveness of an m-learning scenario}

Vavoula and Sharples (2009) have called for a thoughtful and strictly performed evaluation of m-learning scenarios at three levels of evaluation: (1) the usability of the technology (micro level); (2) education/learning (meso level); and (3) organisation/ practicability (macro level). In the current study we focused on the meso level by investigating deeply the learning that takes place in the m-learning scenario. Although 
the usability of the mobile devices (i.e. the micro level) is addressed in a less detailed manner with a questionnaire and field reports, this simple usability evaluation should be sufficient, since we used low-tech devices. The last evaluation level (i.e. macro level) is not tested directly; nevertheless, field reports by experts enabled a rough estimation of the practicability of this scenario, since traditional settings without mobile devices that had been carried out in preceding years are comparable to the current study in terms of teaching personnel, study site, and learning contents.

\section{Formats of visualisation as design principles of mobile learning activities and contents}

Another issue to be addressed by research on m-learning is the design of learning activities and contents when using mobile devices (Milrad 2007). Mobile technologies offer a unique possibility to provide dynamic learning contents on demand in a realworld learning scenario. Although it is still under debate if and under which circumstances learning from dynamic visualisations is superior to learning from static visualisations (Hegarty 2004), one of these circumstances might be the usage of dynamic visualisations in a situated instructional context that is augmented by mobile devices as in the current study.

In general, several benefits and drawbacks of dynamic visualisations have been reported so far in the literature. One characteristic of dynamic visualisations in comparison to static ones is that they deliver information concerning changes of objects and their positions over time (motion: Bétrancourt 2005) as well as information concerning the directions of these changes (trajectory: Rieber 1990). Thus, the congruency principle suggests that if motion changes over time, or trajectory is part of the learning content, dynamic visualisations should be superior to static ones (Tversky, Bauer-Morrison, and Bétrancourt 2002). Moreover, dynamic visualisation formats contain information about the continuous aspects of dynamic processes, which do not have to be inferred by the viewers, as would be the case with static pictures (mental animation: Hegarty 1992). Thus, dynamic visualisations may supplement processes which a learner otherwise would have to conduct for him or herself (supplantation: Salomon 1979). On the other hand, the transience of animations may result in missing important information in the learning content (Lowe 1999). Furthermore, dynamic learning materials might overwhelm learners' cognitive and attentional capacities due to the high information density that they contain.

The biological content domain of identifying fish species relies on identifying static (mainly morphological, e.g. colouration, position of fins) as well as dynamic features, like the behaviour of fishes or their locomotion patterns (e.g. cleaning other fish, swimming mode). Morphological features might be recognised more easily by using static pictures rather than animations, therefore, static visualisation formats could be advantageous in this domain. However, fish behaviour, as well as the characteristics of a movement pattern, is very difficult to infer based on static pictures alone. Additionally, the contents of the dynamic learning material are more consistent with the learning objectives addressed in this study, namely, to identify living species in their natural habitat. Thus, according to the congruency principle dynamic representations might be superior to static ones with regard to conveying these dynamic features. A recent meta-analysis by Höffler and Leutner (2007) suggests that the promises of dynamic visualisations override their drawbacks in biology education in particular. 


\section{Predictions}

Our first hypothesis was that a real-world experience enriched by mobile devices would lead to a significant knowledge gain. We assumed that the advantages of the situated learning scenario would outweigh the focus problem in mobile learning (cf. Göth, Frohberg, and Schwabe 2006). To test this hypothesis, students were tested for their knowledge on different fish species before and after the real-world experience in which they made use of the mobile device. Additionally, because dynamic visualisations reflect the real-world experience much better and because identifying fish species in a real-world environment is what students were trained and tested for, our second hypothesis was that the dynamic learning material would lead to higher knowledge gains than static learning material (Höffler and Leutner 2007). Moreover, our study design also tested whether both factors (enriched real-world experience and visualisation format) would interact with each other.

\section{Methodology}

\section{Participants and design}

The study was conducted during a regular university field course in Marine Biology held in Spain, Costa Brava by zoologists of the University of Tuebingen, Germany. Thirty-five biology students of participated in the course and all of them joined the study ( 22 were female, 13 male). Twenty-one were 3 rd year students, twelve 4 th year students, and two 5th year students. Students were divided into two groups; one of which received static visualisations; the other received dynamic visualisations.

\section{Materials}

\section{Learning materials}

We used two different multimedia DVDs that were developed for this study. One included dynamic real-time videos of 18 different fish species and the other comprised 18 corresponding static sequences consisting of one or two selected freeze-frames of each species extracted from the videos. Both DVDs were arranged in the same way with a master slide including instructions and three slides each with pictures of six species to click on to watch the video or the static frames of the species. Each video and each corresponding sequence started with a black screen on which the name and the size of the fish were displayed. Both DVDs were linked with identical audio-files that provided information about habitat, morphology, behaviour of the species, swimming mode and features unique for this species and necessary to distinguish it from the remaining 17 species in the collection. Each species presentation ended with a black screen displaying the name of the species again. The presentation of the videos was matched in duration to the respective presentations of the static frames (duration between 47 and 53 seconds). The audio-files could be listened to with headphones so students would not disturb each other. During the learning phases one DVD-player and one set of earbuds were shared between two students enabling a basic level of collaboration while both were watching the videos. Since the unique morphological features of a swimming fish species are difficult to perceive we chose one or two images from each real-time video to freeze for a few seconds. The features mentioned in the spoken text were superimposed as labels on the freeze-frames (see example in Figure 1). The dynamic condition displayed these freeze-frames for some seconds 

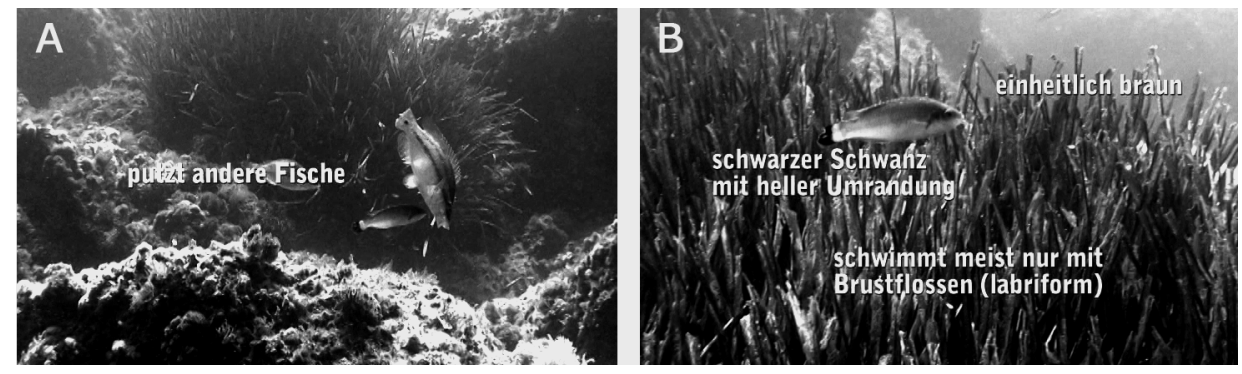

Figure 1. Screenshots of the labelled freeze-frames of the video of Symphodus melanocercus. A. Behavioural aspect. Translation of German text: cleaning other fishes. B. Morphological features, swimming style and colouration. Translation of German text: brown colour (upper right), white edged black tail (middle), swimming exclusively with pectoral fins [labriform swimming mode].

only but displayed behavioural and swimming aspects for most of the time. In the static condition these labelled freeze-frames were presented throughout the whole sequence. The DVDs had a resolution of $576 \times 384$ pixels and the aspect ratio was 16:9. All fish species were filmed at Cap Roig, Spain, Costa Brava by a professional nature documentary producer and biologist in HD-quality film material. The best sequences obtained for the 18 species were extracted from this material and included in the learning materials.

During their initial learning phase with the mobile devices in a classroom students used a preformatted paper sheet (fish species form) with equal space reserved for notes concerning each of the 18 species.

\section{Post-tests}

To measure students' performance in fish identification they had to fill in a first posttest after the learning phase in the classroom and a second post-test after the subsequent snorkelling exercise (see Table 1; unit 5, 7, meso level of evaluation). In these post-tests students were shown 18 real-time videos of the Mediterranean fish species that they had learned on a projection screen in the classroom. These test videos showed different individuals of the species in different local environments arranged in a different order than in the learning DVDs. One point was assigned for each correctly identified species (maximum: 18 points). Each video was approximately 40 seconds long, depending on the species. As the test videos did not contain spoken text or labels, the real-time videos in the post-tests simulated fish observations in the field, which is the qualification biologists are trained for. The test videos were filmed in standard video quality at the same location as the learning materials under regular snorkelling conditions, thereby, simulating real-life conditions for observing marine species.

\section{Mobile devices}

The DVDs were played on portable 7" DVD players (XORO HSD 7100). The weight of one player was $2.0 \mathrm{~kg}$. Students could switch between the three menu slides and start the visualisations by clicking the play button. 


\section{Evaluation questionnaire}

At the end of the study an evaluation questionnaire assessed the usability of the mobile devices (micro level) and the support of the DVDs and the snorkelling activity for learning (meso level). Learners were asked to rate on a 5-point-Likert scale how long they had snorkelled and used the DVD and whether they considered these activities to be conducive to learning.

\section{Procedure}

The study was conducted over three days and organised into eight units (Units 1-8, see Table 1 for details). To parallelise experimental groups, students were initially asked to fill in Questionnaire 1, which tested their prerequisite knowledge and asked for demographic data (Unit 1). Depending on their answers they were assigned to one of the two experimental groups. Units 2 and 3 were designed to convey basic knowledge on snorkelling and fish identification; moreover, students received operating instructions for the mobile devices. During unit 4 (initial learning phase) the participants used the portable DVD players (either dynamic or static material) in the classroom to acquire knowledge on the features needed to identify the 18 most common coastal fishes of the region. Students took notes on their fish species forms. Subsequently, students' performance in fish identification was measured by post-test 1 , in which students identified fish species presented in a video clip. Students were neither allowed to use the learning DVDs nor the fish species forms during testing, or to talk to each other. During a subsequent real-world experience on the beach (snorkelling), students were instructed to identify as many as possible of the 18 fish species introduced to them by the DVD material. They were allowed to discuss their observations and to use the DVD material on the portable DVD players as well as their notes on the fish species forms in between snorkelling. The observations in the water and the use of the learning materials at the beach were kept separate due to the fact that mobile devices and notes were not waterproof. Both groups snorkelled in the same bay, but at different spots which were exchanged halfway through. We chose the bay of Aiguablava, Costa Brava for the snorkelling exercise, because it provides perfect conditions to observe all of the 18 species as well as excellent snorkelling conditions for novices. On the day of the field study, the weather was warm and sunny, visibility in the water was good, and the sea was calm. Experts helped students in the water to find suitable places for fish observation but gave no feedback on fish identification. Furthermore, they observed students interacting with the mobile devices (micro level of evaluation) and compared the practicality of the scenario (macro level) and the effectiveness of learning (meso level) of the current study to field trips of previous years without mobile devices. After snorkelling students' performance was measured again by post-test 2, which was the same as post-test 1 (meso level).

\section{Results}

To evaluate students' learning outcomes obtained by post-test 1 and 2 a mixed-design ANOVA was conducted (meso level of evaluation). Figure 2 shows the mean number of fish species correctly identified by each group in the two post-tests. A main effect of post-tests was found $(F(1,33)=213.12, p<0.001)$ showing that students performed 
Table 1. Course of the 3-day study conducted at the Mediterranean coast of northern Spain, Costa Brava

\begin{tabular}{|c|c|c|c|c|}
\hline Unit & Time & Description & Material used & Location \\
\hline 1 & Day 1, $30 \mathrm{~min}$ & $\begin{array}{l}\text { Students complete questionnaire } \\
\quad 1\end{array}$ & Questionnaire 1 & Classroom \\
\hline 2 & Day 1,90 min & $\begin{array}{l}\text { Introduction to snorkelling: } 30 \\
\text { min oral presentation by } \\
\text { expert; } 60 \text { min practice in } \\
\text { water guided by experts }\end{array}$ & & Classroom; sea \\
\hline 3 & Day 2, $15 \mathrm{~min}$ & $\begin{array}{l}\text { Students receive basics on fish } \\
\text { identification and technical } \\
\text { instructions ( } 15 \mathrm{~min} \\
\text { presentation by expert) }\end{array}$ & $\begin{array}{l}\text { PowerPoint } \\
\text { presentation }\end{array}$ & Classroom \\
\hline 4 & Day 2, $90 \mathrm{~min}$ & $\begin{array}{l}\text { Students' learning phase with } \\
\text { portable DVD player: features } \\
\text { of } 18 \text { fish species to be } \\
\text { observed in the field }\end{array}$ & $\begin{array}{l}\text { Fishidentification } \\
\text { DVD on } \\
\text { portable, fish } \\
\text { species form } \\
\text { for notes }\end{array}$ & Classroom \\
\hline 5 & Day 2, $60 \mathrm{~min}$ & $\begin{array}{l}\text { Post-test } 1 \text {, beamer presentation } \\
\text { for test videos }\end{array}$ & $\begin{array}{l}\text { Fishidentification } \\
\text { test DVD }\end{array}$ & Classroom \\
\hline 6 & $\begin{array}{l}\text { Day } 3,240 \\
\text { min }\end{array}$ & $\begin{array}{l}\text { Real-world experience: fish } \\
\text { identification by snorkelling } \\
\text { (including rest and change of } \\
\text { spot between groups) }\end{array}$ & $\begin{array}{l}\text { Fishidentification } \\
\text { DVD on } \\
\text { portable, form } \\
\text { with notes }\end{array}$ & Sea \\
\hline 7 & Day 3, 45 min & $\begin{array}{l}\text { Post-test } 2 \text {, beamer presentation } \\
\text { for test videos }\end{array}$ & $\begin{array}{l}\text { Fishidentification } \\
\text { test DVD }\end{array}$ & Classroom \\
\hline 8 & Day 3, 30 min & $\begin{array}{l}\text { Students complete } \\
\text { questionnaire } 2\end{array}$ & Questionnaire 2 & Classroom \\
\hline
\end{tabular}

better in the second post-test after the snorkelling exercise $(M=14.51, S D=3.21)$ than in the first post-test $(M=5.60, S D=3.67)$. No main effect for the visualisation format was found $(F<1)$. However, a significant interaction between both factors was observed $(F(1,33)=6.72, p=0.01)$ : Bonferroni adjusted post-hoc tests revealed significant knowledge gains for both groups ( $p<0.01$ for both groups); however, judging by the effect sizes (i.e. partial eta ${ }^{2}, \eta_{p}^{2}$ ), knowledge gains for the dynamic group $\left(\eta_{p}^{2}=0.82\right)$ were more pronounced than those for the static group $\left(\eta_{p}^{2}=0.68\right)$. T-tests did not show any differences between the groups in the first post-tests $\left(M_{\text {dynamic group }}=4.94, S D_{\text {dynamic group }}=2.73 ; M_{\text {static group }}=6.29, S D_{\text {static group }}=4.44\right.$; $t(33)=1.09, p=0.28)$, but revealed a tendency in the second post-test indicating that the dynamic group $(M=15.39, S D=3.17)$ outperformed the static group $(M=13.59$, $S D=3.08 ; t(33)=-1.70, p=0.098)$.

Data from the evaluation questionnaire at the end of the study did not show any significant differences between the two groups. For knowledge acquisition none of the students of the overall sample found the snorkelling activity not helpful at all, 2.9\% found it a little helpful, $37.1 \%$ found it helpful, and $60 \%$ found it very helpful. All students reported that they found the DVD helpful for knowledge acquisition (meso level). The usability of the mobile DVD player was assessed by the frequency of its use. It was used by $68.6 \%$ of all students for $0-15$ minutes and $31.4 \%$ used it for $15-$ 30 minutes (micro level). 


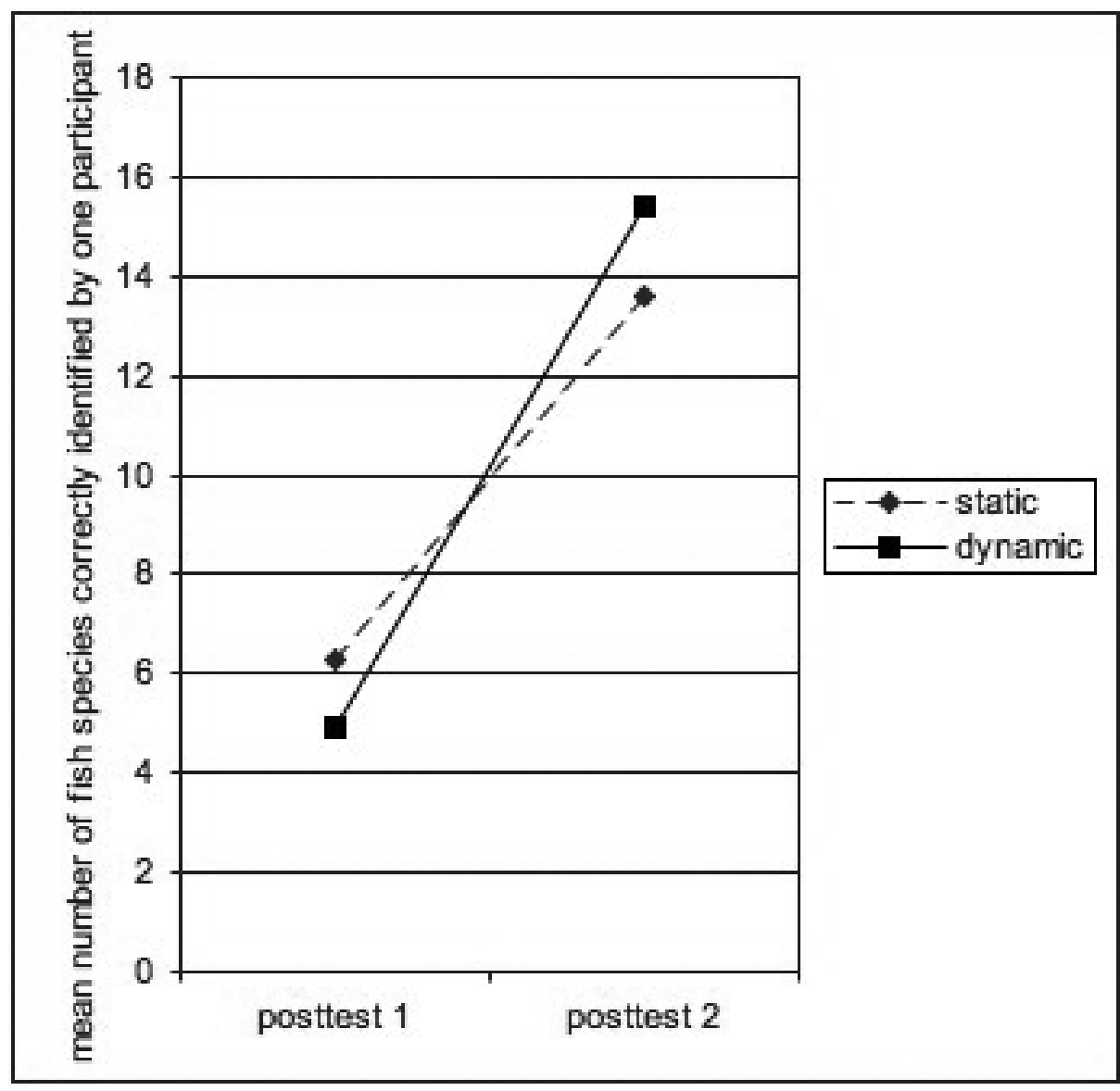

Figure 2. Average performance in the two post-tests as a function of visualisation condition

Furthermore, experts' observations of students interacting with mobile devices (micro level) yielded that students had no problems in operating the devices. The devices turned out to be quite resistant to sand and water splash, however they were not waterproof, so it was impossible to take them into the sea. Due to the light conditions the display was sometimes difficult to use. However, shielding the display against the sun with a hand was usually sufficient to solve this problem. None of the batteries ran out of power during the study. When experts compared the implementation of mobile devices in the current study to field trips of previous years, in which field books instead of mobile devices were used for fish identification, they found learning through the use of mobile devices fits well in the organisational structure of the trips (macro level) and guided more efficient learning (meso level).

\section{Discussion}

In the current study mobile devices were integrated into a real world experience on the beach, where they were used to connect in- and outdoor learning. We considered three levels of evaluation (Vavoula and Sharples 2009). The frequency of use of the DVD players as reported by the evaluation questionnaire as well as field reports of experts 
underline the usability of the mobile device (micro level). Evaluation of the practicability (macro level) indicates that organisation of such a learning scenario can be managed in a regular university course. We focused mainly on the meso level of evaluation investigating whether students found the learning materials helpful for learning and measuring the learning outcomes before and after the snorkelling experience.

Students had no prior knowledge of the 18 Mediterranean fish species and they were only able to identify a few species after the initial learning phase in the classroom. In line with our first hypothesis their knowledge had significantly improved after the snorkelling experience and they found the DVDs and the snorkelling experience supportive for learning. Additionally, experts tutoring this study mentioned that learning with mobile devices was more efficient than learning with traditional field guidebooks as used in former years. This result confirms the conclusion that the realworld experience was highly efficient for learning. It can be hypothesised that knowledge of biodiversity remains inert as long as it is not strengthened by the real-world experience. Thus, our first hypothesis that an enriched real-world experience by use of mobile devices leads to a significant knowledge gain could be confirmed (cf. Bransford et al. 1987; Falk and Dierking 2000). One reason for this finding might be that mobile devices are regarded as highly motivating in general (Jones, Issroff, and Scanlon 2007). Furthermore this result suggests that the focus problem of mobile learning, namely changing the focus of attention from the real world to a specific device, can be solved (Beale 2007). This seems not to have been a problem of the current study, maybe because the mobile devices used were sufficiently easy to handle and were already introduced in the classroom to students so that they were already familiar with them when starting the real-world experience. Additionally, learning was highly structured, as observing species and identifying them with mobile devices were strictly separated (Göth, Frohberg, and Schwabe 2006). Moreover, the mobile DVD players did only offer information needed to solve the task so that students were not distracted by features that they did not really need in this setting (cf. Göth, Frohberg, and Schwabe 2006).

However, we have to reject our second hypothesis concerning the overall superiority of dynamic visualisations as students of both experimental groups performed equally well when looking at the average learning outcomes achieved across both post-tests. Hence, the visualisation format had no direct influence on the overall performance. This finding is consistent with Tversky and colleagues (2002) who state that even in conveying dynamic contents dynamic visualisations often fail to lead to superior learning results compared to static visualisations. Higher cognitive demands of the dynamic visualisation format might have been the reason for this result. Lowe (2004) claims that additional design guidelines based on research about perceptual and cognitive processes are needed to tap the full potential of dynamic visualisations.

According to the results of the current study it seems to be particularly important to investigate the role of dynamic visualisations in different instructional scenarios. In particular, the findings indicate that the potential of dynamic learning materials could be tapped when embedding them in a situated learning scenario. That is, combining dynamic visualisations with an enriched real-world learning experience improved learning to a larger extent than using static visualisations in this combination. Data from this study indicate that the potential of a dynamic presentation format seems to unfold only after an enriched real-world experience made possible by using mobile devices. Even if the dynamic visualisations did not lead to better knowledge 
immediately as would have been reflected in the first post-test, they may have facilitated learning from the real-world experience nevertheless. Maybe fish that were observed during snorkelling could be easier linked to the observations made while watching the DVD, as behavioural patterns and motions (i.e. aspects not visible in the static pictures) could be used as cues for memory access. Moreover, knowledge acquired from dynamic visualisations during the classroom instruction may have remained inert, as long as it was not strengthened by real-world experience (cf. Resnick 1987). It seems that only in a situated learning scenario can videos substitute experiences of experts in some way. However, the current study does not allow deciding on the mechanisms underlying this finding. Nevertheless, it stresses the importance of testing the effectiveness of instructional materials not simply in the laboratory, but of assessing their impact in situated learning contexts facilitated by mobile devices, which may act as moderators for their instructional effectiveness. Maybe combining other unique characteristics of mobile devices with the possibility to provide dynamic visualisations can further strengthen the effect. Finally, all three levels of evaluation of this study indicate that mobile learning is a promising tool to enhance knowledge on fish biodiversity in a situated learning scenario, namely during an outdoor activity that includes snorkelling, and it is a future challenge to expand mobile possibilities further to improve learning in an effective way.

\section{Conclusions}

In the last years m-learning has become an integral part of modern society but less is known about design principles and their effectiveness when integrated in regular curricula. In the current study mobile devices were integrated in a situated learning scenario, whereby different visualisation formats (static vs. dynamic) were made available through them. We decided to compare dynamic and static visualisations on mobile devices instead of comparing a traditional field book with mobile devices for several reasons. First, we tried to keep learning materials as equal as possible to be able to explore the role of the visualisation format aspect irrespective of other unique features of mobile devices. Second, mobile devices are regarded as highly motivating (Jones, Issroff, and Scanlon 2007), hence providing only one group with a mobile device would have possibly resulted in a priori differences in motivation. Third, experimental groups were separated but could see each other during the study. Since seeing each other using different media might have affected the learning outcomes of the participants all groups were provided with learning materials on mobile devices. We did not especially address ethical issues in this study as no content development by or monitoring of the participants occurred. Our results indicate that mobile devices could be well implemented in a situated learning scenario. Furthermore, the current study showed that dynamic visualisations are not superior to static ones at an overall level, but that they unfold their potential only after the real-world experience. Future research needs to look at whether these findings hold when more information to the DVDs is added to make them interesting for an extended target group and when mobile devices that incorporate more features (e.g. a database with a search function, an internet communication platform where users can exchange thoughts) are used. In these cases the focus problem of mobile learning (Beale 2007) may become apparent. It might thus be an interesting question for further research of how to take into account the trade-off between the power of enhanced mobile learning and its possible dangers. 


\section{References}

Beale, R. 2007. How to enhance the experience without interfering with it? In Big issues in mobile learning: Report of a workshop by the kaleidoscope network of excellence mobile learning initiative, ed. M. Sharples, 12-6. Nottingham: Learning Science Research Institute, University of Nottingham.

Bergbauer, M., and B. Humberg. 1999. Was lebt im Mittelmeer? Stuttgart: Kosmos Verlag.

Bétrancourt, M. 2005. The animation and interactivity principles. In Handbook of multimedia learning, ed. R.E. Mayer, 287-96. Cambridge: Cambridge University Press.

Bransford, J.D., R.D. Sherwood, and T. Sturdevant. 1987. Teaching thinking and problem solving. In Teaching thinking skills: Theory and practice, ed. J.B. Baron and R.J. Sternberg. New York: Freeman, Times Books, Henry Holt \& Co.

Brown, A., and J. Campione. 1996. Psychological theory and design of innovative learning environments: On procedures, principles, and systems. In Innovations in learning: New environments for education, ed. L. Schauble and R. Glaser. Mahwah, NJ: Erlbaum.

Chen Y.-S., T.-C. Kao, G.-J. Yu, and J.-P. Sheu. 2004. A mobile butterfly-watching learning system for supporting independent learning. In Proceedings of The $2^{\text {nd }}$ IEEE International Workshop on Wireless and Mobile Technologies in Education 2004, ed. J. Roschelle, T.-W. Chan, Kinshuk, and S.J.H. Yang, 11-18. Washington, DC: IEEE.

Engeström, Y. 1987. Learning by expanding: An activity-theoretical approach to developmental research. Helsinki: Orienta-Konsultit.

Falk, J.H., and L.D. Dierking. 2000. Learning from museums: Visitor experience and the making of meaning. Oxford: AltaMira Press.

Göth, C., D. Frohberg, and G. Schwabe. 2006. The focus problem in mobile learning. In Proceedings of The 4th IEEE International Workshop on Wireless and Mobile Technologies in Education, ed. S. Hsi, Kinshuk, T.-W. Chan, and D.G. Sampson, 153-60. Washington, DC: IEEE.

Hegarty, M. 1992. Mental animation: inferring motion from static displays of mechanical systems. Journal of Experimental Psychology: Learning, Memory, and Cognition 18: 1084-102.

Hegarty, M. 2004. Mechanical reasoning as mental simulation. TRENDS in Cognitive Sciences 8: 280-5.

Höffler, T.N., and D. Leutner. 2007. Instructional animation versus static pictures: A metaanalysis. Learning and Instruction 17: 722-38.

Jones, A., K. Issroff, and E. Scanlon. 2007. Affective factors in learning with mobile devices. In Big issues in mobile learning: Report of a workshop by the Kaleidoscope Network of Excellence Mobile Learning Initiative, ed. M. Sharples, 17-22. Nottingham: Learning Science Research Institute, University of Nottingham.

Kolb, D. 1984. Experiential learning: Experience as the source of learning and development. Englewood Cliffs, NJ: Prentice Hall.

Liu T.-Y., Y.-L Chu. T.-H. Tan and C.-C Chang. 2007. RFID-based ubiquitous learning environment for outdoor learning. In Proceedings of the 7th IEEE International Conference on Advanced Learning Technologies, ed. M. Spector, D.G. Sampson, T. Okamoto, Kinshuk, S.A. Cerri, M. Ueno, and A. Kashihara, 675-7. Washington, DC: IEEE.

Louisy, P. 2002. Meeresfische Westeuropas und des Mittelmeeres. Stuttgart: Ulmer Verlag.

Lowe, R.K. 1999. Extracting information from an animation during complex visual learning. European Journal of Psychology of Education 14: 225-44.

Lowe, R.K. 2004. Animation and learning: Value for money? In Beyond the comfort zone: Proceedings of the $21^{\text {st }}$ ASCILITE Conference, ed. R. Atkinson, C. McBeath, D. JonasDwyer, and R. Phillips, 558-61. Perth, Australia: ASCILITE.

Milrad, M. 2007. How should learning activities using mobile technologies be designed to support innovative educational practices? In Big issues in mobile learning: Report of a workshop by the Kaleidoscope Network of Excellence Mobile Learning Initiative, ed. M. Sharples, 29-31. Nottingham: Learning Science Research Institute, University of Nottingham.

Mitchell, K., and N.J.P Race. 2005. uLearn: Facilitating ubiquitous learning through camera equipped mobile phones, In Proceedings of the 2005 IEEE international workshop on wireless and mobile technologies in education, ed. H. Ogata, M. Sharples, Kinshuk, and Y. Yano, 274-81. Washington, DC: IEEE. 
Naismith, L., P. Lonsdale, G. Vavoula, and M. Sharples. 2006. Literature review in mobile technologies and learning. Bristol, UK: Futurelab.

O’Malley, C., G. Vavoula, J. Glew, J. Taylor, M. Sharples, and P. Lefrere. 2003. Guidelines for learning/teaching/tutoring in a mobile environment. http://www.mobilearn.org/download/results/guidelines.pdf.

Pask, G. 1976. Conversation theory. Applications in education and epistemology. Amsterdam: Elsevier.

Resnick, L.D. 1987. Learning in school and out. Educational Researcher 16: 13-20.

Rieber, L.P. 1990. Animation in computer-based instruction. Educational Technology Research and Development 38: 77-86.

Rogers, Y., S. Price, G. Fitzpatrick, R. Fleck, E. Harris, H. Smith, C. Randel, H. Muller, C. O'Malley, D. Stanton, M. Thompson, and M. Weal. 2004. Ambient wood: Designing new forms of digital augmentation for learning outdoors. In Proceedings of the 2004 conference on interaction design and children: Building a community, ed. A. Druin, J.P. Hourcade, and S. Kollet, 3-10. New York: ACM.

Salomon, G. 1979. Interaction of media, action and learning. San-Francisco: Jossey-Bass.

Sharples, M. 2005. Learning as conversation: Transforming education in the mobile age. In Proceedings of Conference on Seeing, Understanding, Learning in the Mobile Age, 14752. Budapest, Hungary: Hungarian Academy of Sciences.

Sharples, M. 2007. Big issues in mobile learning: Report of a workshop by the Kaleidoscope Network of Excellence Mobile Learning Initiative. Nottingham: Learning Science Research Institute, University of Nottingham.

Sharples, M., J. Taylor, and G. Vavoula. 2005. Towards a theory of mobile learning. In Proceedings of mLearn 2005 Conference, ed. T. Brown and H. van der Merwe, 58. Cape Town, South Africa: mLearn.

Taylor, J., M. Sharples, C. O’Malley, G. Vavoula, and J. Waycott. 2006. Towards a task model for mobile learning: A dialectical approach. International Journal of Learning Technology 2, nos. 2/3: 138-58.

Ting, Y.-L. 2005. Mobile learning: Current trend and future challenges. In Proceedings of the 5th IEEE international conference on advanced learning technologies 2005, 603-7. Washington, DC: IEEE.

Tversky, B., J. Bauer-Morrison, and M. Bétrancourt. 2002. Animation: Can it facilitate? International Journal of Human-Computer Studies 57: 247-62.

Vavoula, G., and M. Sharples. 2009. Meeting the challenges in evaluating mobile learning: A 3-level evaluation framework. International Journal of Mobile and Blended Learning 1, no. 2: 54-75.

Winters, N. 2007. What is mobile learning? In Big issues in mobile learning: Report of a workshop by the Kaleidoscope Network of Excellence Mobile Learning Initiative, ed. M. Sharples, 7-11. Nottingham: Learning Science Research Institute, University of Nottingham. 